\title{
FABIÃO, Carlos. Uma História da Arqueologia Portuguesa: das origens à descoberta da Arte de Côa. Lisboa: CTI, 2011.
}

Thiago do Amaral Biazotto

E-mail: thiago_a_b@yahoo.com.br
Graduando em História pela Unicamp. Bolsista de Iniciação Científica do CNPq.
1 Trecho de "A Portuguesa", o hino nacional de Portugal, escrito por Henrique Lopes de Mendonça em 1890.
Heróis do mar, nobre povo,

Nação valente, imortal,

Levantai hoje de novo

O esplendor de Portugal!"

O interesse dos homens pelo passado sempre se fez presente na espécie humana. Seja através de fontes escritas, seja através de artefatos e resquícios materiais, o desejo de conhecer o que passou em eras remotas se constitui numa atividade ínsita ao próprio ato de pensar. Deste interesse nasceram disciplinas que se ocupam, a piori, do passado, como a História e a Arqueologia. Esta última, em particular, tem passado - nas últimas décadas - por múltiplas discussões epistemológicas, que se propõe a investigar como são concebidas e construídas as interpretações acerca da cultura material. Seguindo esta corrente teórica, o livro de Carlos Fabião - Uma História da Arqueologia Portuguesa: das origens à descoberta da Arte de Côa - revela-se uma obra de grande valor, ao promover uma revisão crítica da ciência arqueológica no Estado lusitano.

Carlos Jorge Gonçalves Soares Fabião - nascido em Lisboa, licenciado em História pela Faculdade de Ciências Sociais e Humanas da Universidade Nova de Lisboa e Doutor em Arqueologia pela Faculdade de Letras da Universidade de Lisboa, onde atualmente leciona - deixa claro seu objetivo logo nas primeiras páginas: "o presente livro trata dos modos como a indagação desse remoto passado se fez presente em Portugal" (p.10) e "podemos dizer que este livro trata de nossa identidade, ou, melhor dizendo, dos modos como ela se foi construindo ao longo dos séculos" (p.11). A partir do pressuposto teórico de que a leitura do passado está enviesada pela época em que é feita, torna-se crível admitir que o primacial alvo de Fabião é apresentar como tais leituras são feitas de acordo com interesses de ordem política, social e econômica e, de forma concomitante, despir a Arqueologia de seu manto de exotismo. Ler suas quase duzentas páginas é uma tarefa assaz agradável, graças a uma linguagem acessível, em associação a um trabalho gráfico primoroso - coroado com belíssimas ilustrações e fotos 
- que funcionam tanto como um complemento ao texto, como um deleite extra aos olhos do leitor.

Divido em cinco grandes eixos temáticos - Os tempos da Sagrada Lei Escrita e dos nossos antepassados Romanos; A Antigüidade como argumento de legitimação política: a Real Academia de História Portuguesa; A Grande Revolução: o evolucionismo e a Antigüidade da terra das formas de vida e do Homem; Antiguidade das Nações e O Século XX - o livro inicia sua reflexão a partir do Mundo Antigo, em particular ao papel dado pelos gregos e romanos à identificação de vestígios do passado com realidades conhecidas através dos relatos mitológicos (p.17). Séculos depois, no Renascimento europeu, houve um resgate deste interesse, com reflexos imediatos no recém-unificado Estado português. Da exegese bíblica e da erudição da leitura de autores clássicos surgiriam as chaves para se chegar às autênticas raízes lusitanas. $\mathrm{O}$ dominicano Giovanni Nanni, em fins do século XV, escreve História, na qual atribuía à "colonização da Península Ibérica a Túbal - filho de Jafet e neto de Noé - que teria aportado quando baixam as águas do dilúvio (...) Túbal seria o primeiro monarca e foi sucedido por seu filho Ibero" (p.21). Na esteira de Nanni, também foram escritas História de Portugal, de Fernando Oliveira (1581) e a obra de Francisco Holanda (1571). Esta última chama atenção por considerar Lisboa "mais antiga que Roma (...) e edificada para o senhor Deus" (p. 27). Também se ocupou deste propósito André de Resende, em sua História da antigüidade da cidade de Évora, ao investigar as relações do moderno Portugal com a antiga Lusitânia romana, bem como entender os porquês do triunfo do cristianismo em terras lusas.

Sendo assim, os pontos de contato entre o Mundo Antigo e o novo Estado português são, nesta época, pensados da seguinte maneira: "o legado clássico fascina, como exemplo, como factor de enobrecimento de terras e lugares e como espaço de reivindicação histórica (...) mas esse passado romano não ofusca, de modo algum, a idéia de que o Reino de Portugal teria sido um lugar onde cedo se afirmou a religião verdadeira" (p.44). Desnecessário mencionar que a "religião verdadeira" era a cristã.

As formas através das quais as tradições clássica e cristã se interligavam continuou nos séculos seguintes, tendo seu fastígio na fundação da Real Academia de História Portuguesa e seu Real decreto de 14 de Agosto de 1721, que apregoava que "se conservem os monumentos antigos, que podem servir para ilustrar e testificar a verdade da mesma história (...) que pode ser muito interessantes à glória da Nação Portuguesa" (p.51). A despeito de sua aparente ineficácia, não deixa de ser basilar uma iniciativa Estatal que versava sobre a preservação - e, quiçá, interpretação - da cultura material no território lusitano.

Embora catastrófico, o grande terremoto ocorrido em Lisboa no ano de 1755 acabou por reforçar os laços seculares entre as províncias lisboetas e o coração do Império, uma vez que no processo de reconstrução da cidade diversos artefatos e construções de origem romana foram descobertos, sendo o mais notável um teatro, detectado em maio de 1798 (p.66).

Outro evento que deu novo fôlego à Arqueologia lusitana foi o início das escavações em Pompéia, em 1748, capitaneadas por Carlos III (1716-1788). Os trabalhos na cidade romana arrasada pelo Vesúvio em 79 d.C. revelaram um passado não apenas marcado por deuses e heróis, mas por pessoas 
comuns em suas atividades cotidianas, o que promoveu - nas palavras de Fabião - "um primeiro esboço de Arqueologia Pública" (p.82), que teve seu efeito ampliado pela escavação do templo romana na cidade de Évora, em 1845, e a fundação da Sociedade Archeólogica Lusitana. Embora de existência efêmera, tal entidade "constituiu uma singularidade no panorama arqueológico português, por se tratar de uma iniciativa nascida e alimentada pela sociedade, sem qualquer investimento estatal. Revela a atitude de uma nova sociedade liberal, burguesa e empreendedora (...)" (p.93).

Neste novo Portugal, é oportuno salientar, "ninguém se preocupava em buscar as provas do cristianismo no reino" (p.91). A arqueologia portuguesa fervia. Fervia a ponto do egrégio escritor lusitano Eça de Queiroz, em seu romance $A$ Relíquia, incluir a personagem Dr. Topsius, um germânico arqueólogo de ofício. Sua descrição é hilariante: "Um indivíduo meio lunático, descuidado no vestuário e nos comportamentos sociais, mas simpático e inofensivo" (p.84).

A verdadeira revolução da Arqueologia Portuguesa, outrossim, seria consumada com a publicação de On the Origin of Species, do naturalista britânico Charles Darwin, em 1859. Se o colossal impacto da obra de Darwin atingiu ciências como Biologia e Botânica, ele não passaria incólume pela Arqueologia. A nova concepção de que "as sociedades humanas passaram a ser entendidas em sentido orgânico, sujeitas a diferentes estados de desenvolvimento que eram diretamente observáveis" (p.97-8) agenciou uma extraordinária mudança de prumo teórico no que concerne ao trato com a cultura material: "cuidar do passado e dos seus símbolos passou a ser responsabilidade social do novo Estado liberal, que a Era das Revoluções instituía por todo o continente" (p.98). Neste proscênio, a Arqueologia torna-se vedete: de reles meio para ratificar informações oriundas de fontes escritas, assume o posto de único meio para constatar a evolução humana. Surge a Comissão Geológica do Reino, em 1857, a cargo de Carlos Ribeiro Pereira da Costa e Nery Delgado. Ocorre em Lisboa, no ano de 1880, o Congrès International d'Anthropologie et d'Archeologie Pré-historiques. A península estava imersa no interesse pela ciência arqueológica.

O advento do Estado-Nação e, por colorário, a invenção do nacionalismo - como se sabe - utilizou-se da Arqueologia, tanto para justificar sua existência, quanto para servir como meio de reivindicação histórica sobre determinados territórios. Antes se buscavam relações entre os povos nacionais e o Império romano. Agora se objetiva encontrar "heróis nacionais", que traduzem uma índole inerente aos povos antigos e que, por consequência, foi herdada pelas modernas populações burguesas. Vercingetórix, na França; Boudica, na GrãBretanha e Arminius, na Alemanha. Todos respondiam a este anseio. Com Portugal não haveria de ser diferente: procura-se agora os lusitanos, povos que se situavam no extremo Ocidente da Península Ibérica antes da expansão romana.

O grande arauto desta busca foi Martins Sarmento e, a partir de sua definição, os lusitanos seriam um povo que "manteve-se no Noroeste da Espanha, com a sua velha língua, os seus velhos costumes, sua velha civilização, enfim, até a conquista romana" (p.136-7). Nesta perspectiva, os portugueses descendiam - de maneira axiomática - deste povo e, por conseguinte, dispunham de uma solidez moral que os marca desde priscas eras. Sarmento, ademais, foi o fundador do Museu Ethnographico Português, que visava 
"representar a parte material da vida do povo português - isto é, tudo o que a esse respeito ethnicamente nos caracteriza" (p.162).

O último capítulo, $O$ século $X X$, versa a respeito da Arqueologia portuguesa no último século, em especial a partir da fundação da Universidade de Lisboa, em 1911. Assim como em grande parte da Europa, os estudos arqueológicos em Portugal, no período anterior às duas Guerras, estavam marcados por um forte traço nacionalista, como exemplificado na assertiva de Manuel Heleno: "a nacionalidade portuguesa, como agregador humano, possuidor de uma unidade moral, está definida, perfeitamente, desde os tempos da pedra polia" (p.171-2). Contudo, esta retórica reacionária caiu por terra ao término da II Guerra Mundial, tornando-se "absolutamente anacrônica" (p.172).

Nesta altura do livro, o leitor pode sentir a ausência de relatos mais pormenorizados acerca das pesquisas arqueológicas realizadas durante o governo do ditador António de Oliveira Salazar (1889-1970). Em que pese esta ausência não representar decréscimo na qualidade da obra, cabe a sugestão para uma edição futura, ou uma eventual nova publicação voltada ao tema.

As últimas duas décadas do século $X X$ foram de grande importância para a arqueologia lusitana, com a criação do Instituto Português de Patrimônio Cultural, em 1980, e a promulgação da Lei de Bases de Patrimônio Cultural, em 1985 (p.179). Não obstante, o grande marco foi a descoberta do vale de Côa - em 1991 - "um enorme conjunto de gravuras rupestres, muito detalhado, em estilo paleolítico, com cerca de 20.000 anos" (p.180) e que "pelo carácter absolutamente extraordinário do conjunto, a UNESCO classificou a arte de Côa como patrimônio da Humanidade, em 1998" (p.181). O achado, e posterior tombamento, resultou em grande reconhecimento do local, que teve como consequência uma maior geração de receitas, bem como uma interação mais aguda entre as populações locais. Em suma: "o patrimônio arqueológico ocupa um espaço cada vez mais importante no quotidiano da população" (p.182).

Ao escrever Uma História da Arqueologia Portuguesa: das origens à descoberta da Arte de Côa, Fabião não somente nos apresenta um belo relato acerca dos estudos da cultura material em terras lusitanas: ele mostra com a ciência em geral, e a Arqueologia em especifico, está ligada a interesses e motivações políticas, sociais e econômicas. E, se por um lado, tais interesses podem resultar em opressão e discriminação, por outro, iniciativas ligadas à preservação do Patrimônio podem representar um salutar alvitre para as populações locais. Nessa linha, o livro de Fabião não nos faz representar somente a Arqueologia Portuguesa. Faz repensar a Arqueologia como um todo. 